\title{
Uma cidade de transformações: os casos do colégio Marista e do Instituto de Psiquiatria Luiz Inácio no Recife
}

\author{
Maria Rita Ivo de Melo Machado* \\ mariaritamachado@yahoo.com.br
}

Renan Moura de Freitas**

renanmourafr@gmail.com

\section{Resumo}

Esse artigo tem como objetivo analisar as atuais transformações ocorridas no centro urbano do Recife, tomando como referência de análise os imóveis especiais de preservação. Nesse sentido, o objeto de estudo levou em consideração as edificações e o entorno do Colégio Marista e do Instituto de Psiquiatria Luiz Inácio, ambos localizados no bairro da Boa vista, na cidade do Recife - PE. Tal estudo é importante para promover um olhar mais crítico e sistemático sobre a cidade, além de direcionar a importância dos IEP's para a construção de sua identidade.

\section{Palavras-chave}

Recife; Imóveis especiais; patrimônio

A city of transformations: the case of Marista High School and the institute of

Psychiatry Luiz Inácio in Recife

\begin{abstract}
This article aims to analyze the current transformations occurring in the urban center of Recife, taking as reference the analysis of special preservation properties. In this sense, the object of study took into account the buildings and surroundings of the Marista high school and the Institute of Psychiatry Luiz Inácio, both located in the Boa Vista neighborhood, in the city of Recife - PE. Such a study is important to promote a more critical and systematic view of the city, in addition to directing the importance of the IEPs to the construction of its identity.
\end{abstract}

\section{Keywords}

Recife; Special properties; patrimony 


\section{Introdução}

O título adotado para esta pesquisa revela grandes desafios, uma vez que os estudos do espaço urbanos do Recife estão cada vez mais numerosos em virtude das suas constantes transformações. Aqui, será possível discutir alguns elementos que rodeiam a vida urbana da cidade e intervêm diretamente nas suas instituições, na paisagem e na identidade. Dessa maneira, esses elementos justificam os termos do título deste trabalho: "Uma cidade de transformações", pois suas intervenções reestruturam, modificam e atribuem novos componentes simbólicos ao espaço urbano.

A cidade do Recife passa por várias transformações que modificam os seus olhares. Seja pela própria população ou por quem está fora dela, a forma como se observa a cidade vem-se caracterizando por mudanças em sua estrutura arquitetônica, social e institucional. Nesse sentido, a pesquisa desses novos ambientes urbanos é essencial para se analisar com frieza quais as intenções, objetivos e interesses por trás dessas transformações. Esse trabalho se propõe analisar algumas dessas mudanças, principalmente com vista àquelas relacionadas ao patrimônio histórico da cidade, que representam aspectos consideráveis da identidade urbana. Para isso, utilizaram-se os casos do Instituto de Psiquiatria Luiz Inácio e do Colégio Marista, ambos localizados no bairro da Boa Vista, na Avenida Conde da Boa vista.

Não por acaso, a escolha dessas instituições se deu pela particularidade histórica de cada uma. Porém, algo em comum liga a formação dessas identidades arquitetônicas no Recife: ambas proporcionaram espaços de vivência no cotidiano de muitos cidadãos. O início do funcionamento do Colégio Marista, anunciado pelo Diário de Pernambuco em Janeiro de 1924 com o slogan intitulado "Edificação Inteiramente Nova na Rua Conde da Boa Vista $\mathrm{N}^{\mathrm{o}} 385$ ", sinalizava o começo de atividades educacionais que durariam vários anos e construiriam a formação escolar de vários jovens da cidade. Sua administração estava a cargo dos chamados Irmãos Maristas, que, após se instalarem em terras pernambucanas em 1910, desenvolveram trabalhos voltados à educação e evangelização. $\mathrm{O}$ encerramento das atividades da escola se deu em 2002 e, posteriormente, a área foi comprada pelo grupo LUNA, responsável pela rede varejista do Atacado dos Presentes. Depois de quase 80 anos, no dia 13 de Dezembro de 2002, uma missa ocorrida no que era a capela da escola marcou o encerramento das atividades. A solenidade reuniu o pároco da escola e vários exalunos e professores emocionados com a eventualidade (COLÉGIO MARISTA SÃO LUÍS, 2016).

Essa ligação com o espaço responsável por promover experiências afetivas também pode ser visualizada no caso da formação histórica do Instituto de Psquiatria Luiz Inácio. Sua edificação remete ao final do século XIX, quando já se tem registro da sua presença nos mapas do Recife. Acredita-se que incialmente suas estruturas serviram como residências. Posteriormente, esse espaço recebeu a chamada Maternidade Santa Rita e, ao seu fim, deu lugar ao Instituto de Psiquiatria, o qual foi fundado em 1961 pelo médico Luiz Ignácio de Andrade Lima Neto (LIMA, 2016). Após anos de atividades e tratamentos com os mais variados pacientes, essa instituição pediu desativação à Prefeitura do Recife, desmontando cerca de 273 leitos. Dessa maneira, esse imóvel faz parte da história da psiquiatria pernambucana e da memória dos seus agentes envolvidos, como pacientes, médicos e funcionários.

Para considerar essas duas instituições e sua relação com o objetivo da pesquisa, tomar-se-á como referência a atual legislação sobre o uso e ocupação do solo do Recife e suas contradições em relação à flexibilização do uso do terreno em que edificações protegidas estão 
localizadas ${ }^{1}$. Tal flexibilidade permite que a loja de varejo do Atacado de Presentes se expanda dentro do terreno do Colégio Marista e a especulação imobiliária levante um edifício empresarial e um residencial no mesmo espaço de solo do sanatório. Analisar isso é importante para se entender os aspectos negativos e positivos dessas contruções e entender o valor histórico dos Imóveis Especiais de Preservação (IEP's).

A partir dessas considerações, essa pesquisa se insere na problemática da constante onda de verticalização inadequada em função da disformidade com as edificações de preservação. No caso deste estudo, o Instituto de Psiquiatria Luiz Inácio foi alvo desse processo de verticalização, a qual realizada de maneira indiferente, não levou em conta o contexto cultural da edificação já consolidada. Além disso, outro problema observado na discussão será a notada necessidade de expansão, reogarnização e infiltração por parte das grandes empresas comerciais. Essa nova exigência de lugares será colocada em confronto com a edificação do Colégio Marista, instituição escolar que resguarda e desperta memórias, crescida como parte da identidade da cidade. Nesses dois casos, o Instituto e o Colégio, está inserida, ainda, a problemática de uma paisagem urbana construída na ótica da predominância exagerada de determinados agentes urbanos.

Em relação à metodologia, foi traçada a análise das legislações relacionadas com a problemática, principalmente a lei municipal que define o regimento e os Imóveis Especiais de Preservação (IEP's) do Recife e a Lei de Uso e Ocupação do Solo (LUOS). Busca-se responder à seguinte questão: A lei municipal que define o regimento e os Imóveis Especiais de Preservação é eficiente para a preservação dessas edificações? Nesse sentido, também se tornou essencial a observação da estrutura, organização e projetos dos locais, por meio de visitas, mapas, fotos e jornais. Além disso, foi realizado um estudo sobre os diferentes tipos de intervenções arquitetônicas, visando a estabelecer as consonâncias e dissonâncias com as edificações já estabelecidas. Ultilizou-se, ainda, de teóricos relacionados ao espaço urbano para fundamentar a discussão, como Roberto Lobato Corrêa, Milton Santos e Nivaldo Vieira de Andrade Junior. O críterio usado para definição dos recursos metodológicos partiu da perspectiva de buscar discutir as transformações/ contradições relacionadas ao objeto de estudo, considerando seus valores históricos e contribuições significativas para a construção de uma memória social da cidade.

Este artigo foi organizado em três tópicos. O primeiro deles trata da fundamentação conceitual de edificações antigas, paisagem e os agentes formadores da cidade. Posteriormente, será traçado o processo legislativo em torno da problemática dessa pesquisa, no qual se lançará a base para compreensão. Em seguida, as próximas seções formam o ponto-chave do estudo, pois analisam que a descaracterização dos imóveis não é o único problema da intervenção em edificações já consolidadas.

\section{Fundamentação}

As alterações das estruturas pelas quais se configuram a cidade do Recife, remete a aspectos conceituais que são essenciais para localizar esta pesquisa dentro de uma fundamentação científica. Nos termos do objetivo do estudo, focalizou-se uma análise 
do que é rugosidade, paisagem e os agentes constituintes do espaço urbano.

\section{O antigo Colégio Marista e o Instituto de Psiquiatria} Luíz Inácio, ambos localizados na Avenidade Conde da Boa Vista, são edificações históricas, ou seja, que fazem parte da constituição da cidade e aprensentam, em suas edificações, argumentos indentitários representantes de sua memória. A presença dessas construções em meio a modernos prédios e empreendimentos que surgem cada vez mais aceleradamente, caracterizam essas antigas construções como rugosidades, na medida em que se considera a perspectiva de Milton Santos:

Chamemos de rugosidade ao que fica do passado como forma, espaço construído, paisagem, o que resta do processo de supressão, acumulação, superposição, com que as coisas se substituem e acumulam em todos os lugares. As rugosidadesse apresentam como formas isoladas ou como arranjos. (SANTOS, 1996, p. 113).

Desse modo, as rugosidades se constituem como parte da história impressa materialmente na cidade. Por isso, serão considerados o Colégio e o Instituto como elementos que formam essas rugosidades, tendo em vista que são edificações que carregam parte da memória do Recife.

No caso do presente estudo, tendo em vista que também se constituirá de analise das transformações que acontecem no entorno dessas rugosidades, consequentemente, a paisagem será um fator que receberá influencia desse processo transformador. Esse processo de transformações revela o resultado dos interesses de agentes urbanos responsáveis por produzir o espaço da cidade na atualidade. Entretanto, é de conhecimento que a paisagem não se modifica apenas no presente, mas também ao longo das relações sociais e estruturais da cidade em sua história. Portanto, será compreendido o conceito de paisagem como o reflexo da sociedade no decorrer do tempo, uma vez que:

A paisagem é uma forma histórica específica, que se explica por meio da sociedade que a produz, um produto da história das relações materiais do homem que a cada momento adquire uma nova dimensão, é especifica de um determinado estágio do trabalho vinculado à reprodução do capital. (CARLOS, 2008, p. 85)

A discussão sobre o uso do terreno no entorno das construções históricas por parte das empresas responsáveis pelas transformações anteriormente mencionadas, remete a aspectos conceituais que serão discutidos a seguir.

Considerando a cidade como espaço urbano, ela se torna um lugar de expressões dos agentes sociais. Esses agentes realizam práticas resultantes na reoganização do espaço que se forma por criação

\section{[...] de novas áreas ao espaço urbano, densificação do uso do solo, deterioração de certas áreas, renovação urbana, relocação diferenciada da infra-estrutura e mudança, corercitiva ou não, do conteúdo social e econômico de determinadas áreas da cidade. (LOBATO, 1989, p. 11)}

Desse modo, considerando que os agentes sociais são essenciais para construção do espaço urbano, vale identificar quais são eles, suas funções, seus conflitos e seus interesses. Segundo Lobato (1989), os grupos formadores do espaço urbano são os proprietários dos meios de produção, sobretudo as grandes empresas comerciais e os industriais, os proprietários fundiários, os promotores imobiliários, o Estado e os grupo social dos excluídos.

Para uma melhor metodologia, considerando a análise em relação ao Colégio Marista e ao sanatório, é 
contundente examinar mais a fundo os grupos dos proprietários dos meios de produção e dos promotores imobiliários. Esses dois grupos têm interferência direta na modificação da paisagem urbana do Colégio e no Instituto de Psiquiatria. Mais precisamente, os promotores imobiliários atuando sob o sanatório e os proprietários dos meios de produção, bem como as grandes empresas, no Colégio.

Uma das principais características dos promotres imobilíários é o fato de formarem um grupo de agentes, que, por meio da incorporação, realizam, pela mediação do gestor, a transformação do capital em imóvel. A localização, o tamanho das unidades e a qualidade do prédio que serão construídos são definidos na incorporação, assim como as decisões de quem vai construí-lo, a propaganda e a venda das unidades.

A edificação do sanatório, que sofre devido à ação desses promotores imobiliários, recebe intervenção em sua paisagem no seu próprio terreno devido à ação desses incorporadores. Essa intervenção acontece de maneira desimpedida, onde os empresários atuam praticamente livres no solo, havendo poucas restrições por parte da legislação, como a determinação do percentual mínimo de solo natural, os recuos mínimos a partir do limite do lote e a área máxima a ser construída (dada em função do coeficiente construtivo de cada zona legislativa da cidade). Além disso, a legislação não explicita uma tipologia a ser seguida quando a construção for realizada num terreno em que existe uma edificação preservada. O resultado disso deixa clara a vulnerabilidade visual daquele do lugar.

Já os proprietários dos meios de produção, ou seja, grandes empresas comerciais e proprietários industriais, assumem posição determinante nas transformações ocorridas com o Colégio Marista. Ainda segundo Lobato:

Os grandes proprietários insdustriais e das grandes empresas comerciais são, em razão da dimensão de suas atividades, grandes consumidores de espaço. Necessitam de terrenos amplos e baratos que satisfaçam requisitos locacionais pertinentes às atividades de suas empresas - junto ao porto, às vias férreas ou em locais de empla acessibilidade à população etc. A terra urbana tem assim, em princípio, um duplo papel: o de suporte físico e so de expressar diferencialmente requisitos lacacionais específicos às atividades. (LOBATO, 1989, p. 13).

Traduzindo isso para o caso do colégio, observa-se o avanço do grupo Luna (Atacado dos Presentes) em direção ao que resta do patrimônio do Colégio Marista. O Atacado já se encontra instalado nos espaços do terreno que pertenciam aos ambientes do colégio. Até o momento, a edificação da loja de varejo se encontra no lugar do que um dia foi a quadra, uma piscina e uma capela. Restando apenas a dependência principal do Colégio. A necessidade de espaço dos comerciantes de que fala Lobato e, nesse caso, necessidade de espaço cada vez maior, resultou num projeto de expansão dessa loja, cuja edificação ficará menos de 10 metros da sede restante do Marista. Essa problemática será discutida mais adiante.

Com isso, percebe-se que as transformações ocorridas nessas duas áreas em questão acompanham a tendência da cidade de desvalorização do seu contexto cultural a partir dessas formas de intervenção nas edificações. A conceituação de Lobato em relação aos processos e formas que adquirem a cidade, facilmente podem ser associados à essa perpepctiva:

A grande cidade capitalista é o lugar privilegiado de ocorrência de uma série de processos sociais, entre os quais a acumulação de capital e a reprodução 
social têm importância básica. Estes processos criam funções e formas espaciais, ou seja, criam atividades e suas materializações, cuja distribuição espacial constitui a própria organização espacial urbana. (LOBATO, 1989, pag. 36).

A concepção que foi possível visualizar nos casos analisados é de uma modelagem da cidade do Recife com a atribuição de importância exagerada à acumulação de capital, refletindo isso na organização espacial urbana da cidade. Tanto no caso do Instituto de Psiquiatria quanto no Colégio Marista existe uma mentalidade de indiferença em relação ao contexto visual e cultural das suas construções históricas, causadas pelos interesses desse capital. Os terrenos das duas edificações ocupadas dessa maneira demonstram não só essa nova roupagem capitalista a que a cidade está submetendo-se, como também revelam um munícipio que desvaloriza aspectos históricos e centros de memória quando colocados frente aos interesses de determinados agentes.

\section{O Processo legislativo}

Roberto Magalhães, ex-prefeito da cidade do Recife, sancionou, em 22 de julho de 1997, a lei municipal número 16.284/97, na qual "Define os Imóveis Especiais de Preservação - IEP, situados no Município do Recife, estabelece as condições de preservação, assegura compensações e estímulos e dá outras providências".

Os Imóveis Especiais de Preservação (IEP's) são imóveis notáveis que fazem parte da história da cidade e possuem grandes expressões arquitetônicas que constroem o patrimônio cultural do Recife. Mais do que simples imóveis, essas edificações carregam consigo uma história própria, um despertar de memórias e uma identidade social. Dessa maneira, é essencial uma gestão política que cultue essa preservação e mantenha vivo esse ciclo, dando à cidade uma personalidade pró- pria. Sua preservação deve ser feita, assim, pela gestão do munícipio em conjunto com a população, indo de acordo com os termos da Constituição Federal e da Lei Orgânica Municipal.

Embora a lei de 1997 definise uma lista de imóveis selecionados que se constituiriam Imóveis Especiais de Preservação, o Instituto de Psiquiatria Luiz Inácio e o Colégio Marista só vieram a ser inclusos posteriormente, a partir de decretos da Prefeitura do Recife, por meio de João da Costa Bezerra Filho e Geraldo Júlio, respectivamente:

Decreto $n^{o} 26.552$ de 13 de julho de 2012:

Art. $1^{\circ}$. Os imóveis de $n^{o}$ 1509, 1531 e 1533 da Avenida Conde da Boa Vista, Bairro da Boa Vista, local onde funcionou o Instituto Psiquiátrico do Recife, passam a ser classificados como Imóveis Especiais de Preservação, nos termos da Lei 16.284 de 22 de janeiro de 1997. (RECIFE, 2012).

Decreto $n^{\circ} 27.888$ de 09 de abril de 2014:

O imóvel situado na Avenida Conde da Boa Vista, $n^{\circ} 358$, bairro da Boa Vista, Municipio do Recife, Estado de Pernambuco, passa a ser classificado como Imóvel Especial de Preservação, nos termos da Lei Municipal $n^{\circ} 16.284$, de 22 de janeiro de 1997. (RECIFE, 2014).

Tendo em vista que o Instituto de Psiquiatria Luiz Inácio e o Colégio Marista são imóveis que devem ter suas edificações preservadas, vale analisar a legislação que regula esses imóveis, no caso a lei 16.284/97, e identificar nossa problemática que começa desde o seu conteúdo.

Nessa lei municipal, o seu artigo $6^{\circ}$ define que os terrenos dos IEP's seguem o potencial construtivo da zona estabelecida pela LUOS (Lei de Uso e Ocupação do Solo): "Será assegurado aos IEP, definidos nesta 
Lei, o potencial construtivo do terreno do Imóvel preservado, estabelecido na Lei no 16.176/96 - LUOS para a zona onde se situa o aludido imóvel.” (RECIFE, 1997). O potencial construtivo se refere à quantidade em área que o empreendedor pode construir em cada terreno. Esse potencial ou coeficiente é designado pela LUOS, que estabelece zonas legislativas para toda a cidade do Recife. Para saber quanto se pode construir, multiplica-se a área total do terreno por esse coeficiente.

No caso dos terrenos do Instituto de Psiquiatria Luiz Inácio, o coeficiente construtivo é de três. Isso acontece por ele estar na ZAC (Zona de Ambiente Construído) Moderada, que é a zona majoritária do centro continental do Recife. Por ter havido um remembramento de três terrenos por parte da incorporadora, a área possível para construção teve um aumento extremo.

Vale ressaltar que o remembramento do terreno está dentro dos termos da legislação que regula os IEP's. Ao permitir o remembramento de terrenos que contêm IEP's, o resultado é que a legislação acaba dando legalidade para um forte adensamento construtivo: "Poderá ser autorizado o remembramento do terreno do IEP, na forma da legislação pertinente, desde que não descaracterize o imóvel preservado." (RECIFE, 1997).

Será discutido adiante que a condição de ilegalidade atribuída pela lei à descaracterização do imóvel não é suficientemente capaz para promover a preservação do que é patrimônio cultural da cidade. Por isso, já cabe a indagação de que a ideia de preservação proposta por lei aos IEP's, no mínimo, também garante um alto potencial construtivo por parte das empresas instaladas no mesmo terreno. No caso do Colégio Marista, o coeficiente de construção é ainda mais alto por se inserir na ZECP (Zona Especial de Centro Principal), no Setor de Centro Consolidado (SCC). Essa zona é constituída pela área do Centro Principal, onde já se encontra consolidada em termos de morfologia urbana, tendo coeficiente sete. Isto é, permitindo construir uma área total sete vezes maior que a área do terreno.

O que ocorre nesses dois casos é que esses imóveis especiais de preservação são "engolidos" esteticamente pelas construções novas, desfigurando o imóvel especial e descaracterizando a própria paisagem no entorno da edificação protegida em detrimento da atuação desses novos agentes urbanos. Como será visto, os futuros empreendimentos do atual Atacado dos Presentes e as duas torres de mais de vinte pavimentos quase que justapostas formarão um retrato dessa relação de luta entre o que é histórico e o que é novo dentro de um mesmo terreno. Revela, ainda, a existência de uma legislação que deixa a desejar em relação aos IEP's.

\section{A descaracterização não é o único problema}

Como relatado anteriormente, a lei municipal 16.284/97 define orientações em relação aos Imóveis Especiais de preservação e protege essas edificações. Isso fica muito claro em seu artigo $9^{\circ}$, que descreve as condições de preservação dos IEP's:

Não será permitida nos IEP qualquer intervenção que implique em:

I - demolição;

II - descaracterização dos seus elementos originais;

III - alteração da volumetria e da feição da edificação original. (RECIFE, 1997)

Diante desses itens da Lei municipal, faz-se o seguinte questionamento: a não descaracterização da edificação original é o que configura a proteção dele? A quebra do padrão construtivo do entorno (e, principalmente, do terreno) dos IEP's não se caracteriza como uma má intervenção? Para discutir esses levantamentos, 
é necessário fundamentar essa prerrogativa que caracteriza a quebra do padrão construtivo já estabelecido como uma forma não planejada e pouco meditada de intervenção.

Nivaldo Andrade (2006), em sua dissertação intitulada Metamorfose Arquitetônica. Intervenções projetuais contemporâneas sobre o patrimônio edificado, estabelece os níveis possíveis de intervenções arquitetônicas que podem ser realizadas em edificações já consolidadas. O autor demonstra que a consonância e a dissonância da edificação nova com a antiga, na sua externalidade, podem ser niveladas considerando seis aspectos ligados à sua forma: volumetria, implantação, escala, densidade ou massa, ritmo e cores ou texturas dos materiais de acabamento. Espera-se que uma intervenção tenha mais de um desses aspectos em sua constituição.

Quanto à volumetria, o autor enfatiza que "Uma intervenção em dissonância no que se refere à volumetria se dará através da inserção de um novo volume realizado com formas distintas daquelas utilizadas na preexistência edificada." (ANDRADE, 2004, p. 200). Outro aspecto é quanto à implantação:

Implantação equivale à localização do novo objeto arquitetônico - seja ele a ampliação de um edifício existente, a complementação de um edifício arruinado ou mesmo um edifício absolutamente novo - com relação ao espaço urbano e às preexistências com as quais se encontra em relação visual - o edifício original que foi ampliado, as ruinas complementadas ou o conjunto em que se insere a nova edificação, respectivamente. (ANDRADE, 2004, p. 202)

Quanto à escala:

A escala diz respeito à relação entre as dimensões da nova arquitetura e aquelas da preexistência na qual a intervenção ocorre. A nova arquitetura será conside- rada consonante com a preexistência nos casos em que as suas dimensões gerais corresponderem aproximadamente àquelas existentes no entorno. (ANDRADE, 2004, p. 205)

Quanto à densidade ou massa:

\begin{abstract}
"Este aspecto corresponde à massa, densidade ou peso aparente do objeto arquitetônico. A densidade pode ser considerada um aspecto intrinsecamente vinculado ao volume, na medida em que ela pode reforçá-lo ou esvanecê-lo, dependendo dos materiais de construção utilizados" (ANDRADE, 2004, p. 210)
\end{abstract}

Quanto ao ritmo:

$O$ ritmo se refere à cadência estabelecida pela repetição de determinados elementos utilizados na composição das superfícies-limite do objeto arquitetônico e que configuram a sua aparência: fenestração (aberturas), estrutura (quando aparente e distinguivel dos demais elementos que compõem o objeto arquitetônico), elementos de decoração salientes ou escavados na fachada, mudança de materiais ou de cores de acabamento, etc. (ANDRADE, 2004, p. 213)

Quanto às cores ou texturas dos materiais de acabamento: "[São as] características dos materiais utilizados nas superfícies-limite da nova arquitetura, em relação com aqueles utilizados nas preexistências. Estamos nos referindo às texturas e, principalmente, às cores." (ANDRADE, 2004, p. 217).

Nesse sentido, em termos de intervenção arquitetônica em um sítio já consolidado, a consonância pode ser atingida quando respeitadas as unidades que compõem a forma da edificação mais antiga. Dessa maneira, a intervenção ficará consonante com o seu entorno, dentro dos aspectos preexistentes. Já a dissonância acontece na situação contrária: a edificação nova não atinge 
nenhum ou alguns dos aspectos relacionados à forma da edificação antiga.

No caso do presente trabalho, estabelecer-se-á uma análise das intervenções realizadas nos lotes dos IEP's estudados, atentando para as diferentes perspectivas entre a forma das edificações novas e antigas. pacto na congruência e nos desenhos da paisagem urbana.

Ainda na figura, sinalizados em cores vermelhas, estão marcados os ritmos das aberturas das edificações. O ritmo das fachadas dos edifícios novos estão em dissonância com a edificação antiga, tanto pela dimensão horizontal quanto na vertical.

Os materiais e cores utilizados nas edificações novas também estão em dissonância em relação ao sanatório.

\section{O Instituto de Psiquiatria Luiz Inácio}

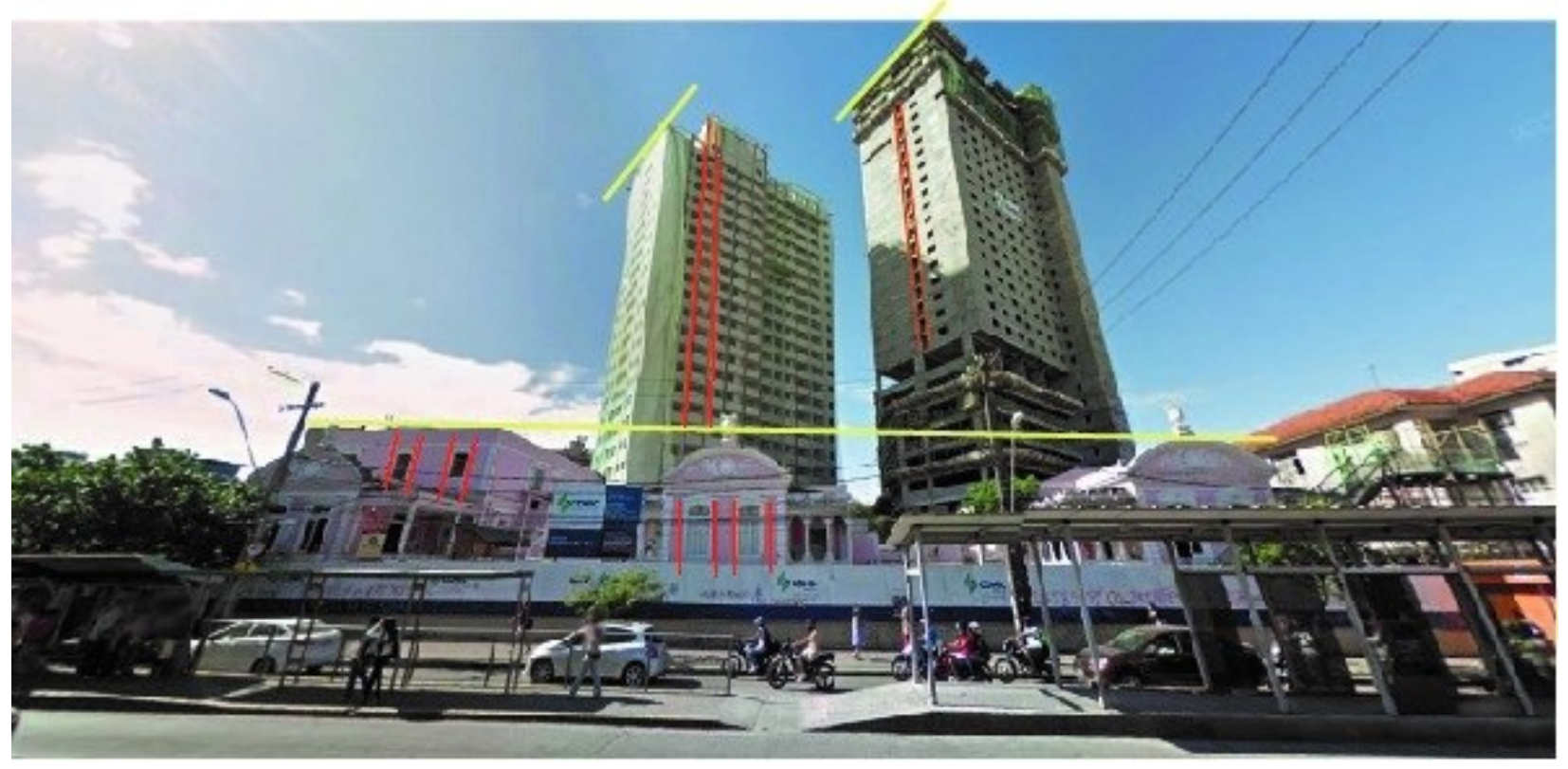

Imagem 1-O antigo Instituto de Psquiatria Luiz Inácio (IEP) e as novas torres construidas ao fundo. Image 1-The former Institute of Psychiatry Luiz Inácio (IEP) and the new towers built in the background. Fonte: Google Maps e editado pelo autor (2016).

Na imagem 1 acima, está sendo mostrado em primeiro plano o antigo sanatório Luiz Inácio do Recife e, ao fundo, estão os novos empreendimentos. Essas novas edificações se localizam no mesmo terreno do sanatório, formadas pelo empresarial Grand Tower Boa Vista ao lado direito e o edifício residencial Boa Vista à esquerda.

Marcadas em linhas amarelas, estão sendo identificadas as escalas das edificações. Como pode ser visto, as escalas das edificações novas estão em dissonância com o conjunto antigo, no qual possui um máximo de 10 metros de altura, enquanto as recentes instalações possuem mais de 100 metros, causando um grande im-
Os edifícios em construção utilizam pastilhas de cerâmicas brancas em seu acabamento (observar o residencial à esquerda da imagem), enquanto no sanatório predomina a cor rosa e acabamento em reboco simples.

Quanto à relação de densidade entre as edificações novas e antiga, apesar do sanatório possuir inúmeras fenestrações, o que sobressai é a parte cheia, maciça, de suas fachadas. Assim sendo, as edificações em construção estão em consonância com a antiga, por possuírem mais espaços preenchidos que vazios.

$\mathrm{Na}$ imagem 2 abaixo, é possível ver as tipologias e as volumetrias simplificadas dos edifícios encontrados no terreno do sanatório. O croqui da direita representa o 
IEP, com sua tipologia de pátio e volumetria marcada por blocos iguais que são conectados por outros menores que servem de passarela. Já o croqui da esquerda representa as duas edificações que estão sendo construídas, ambas têm a tipologia pódio, com um embasamento mais largo e de menor altura, juntamente com uma torre. Assim, em relação à volumetria, as edificações novas estão em dissonância com a antiga.

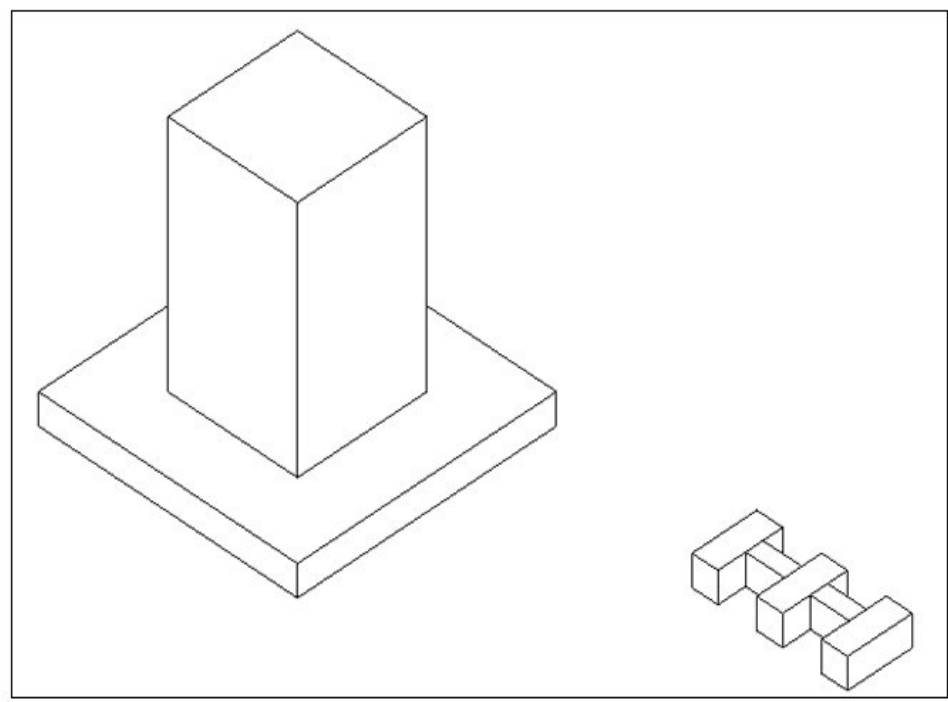

Imagem 2-Tipologias das edificações presentes no lote do sanatório Luiz Inácio.

Image 2-Typologies of the buildings present in the lot of the sanatorium Luiz Inácio.

Fonte: elaborado pelo autor (2016)

A tipologia do edifício é o que define e marca a linguagem arquitetônica da sua composição, independente de arquiteto e idealizador. Logo, uma unidade tipológica e arquitetural é alcançada quando a transição de uma tipologia para outra acontece suavemente.

Para além da análise dessas diferentes formas arquitetônicas apresentadas, também é importante frisar que a modificação da paisagem em si se torna um componente que deve ser discutido. Observando as imagens 3 e 4 abaixo, é possível estabelecer um dado comparativo em relação às mudanças na paisagem:

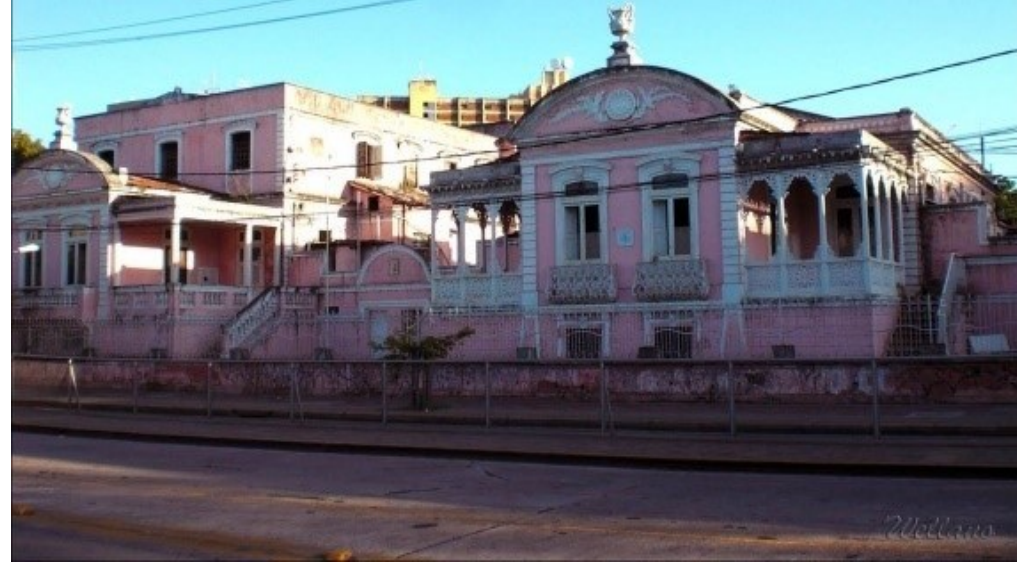

Imagem 3-Instituto de Psiquiatria Luiz Inácio, 2012.

Image 3-Institute of Psychiatry Luiz Inácio, 2012.

Fonte: Disponível em: http://hallsocial.leiaja.com/tags/instituto-depsiquiatria-luiz-inacio. Acesso em: 10 de jun. 2016.

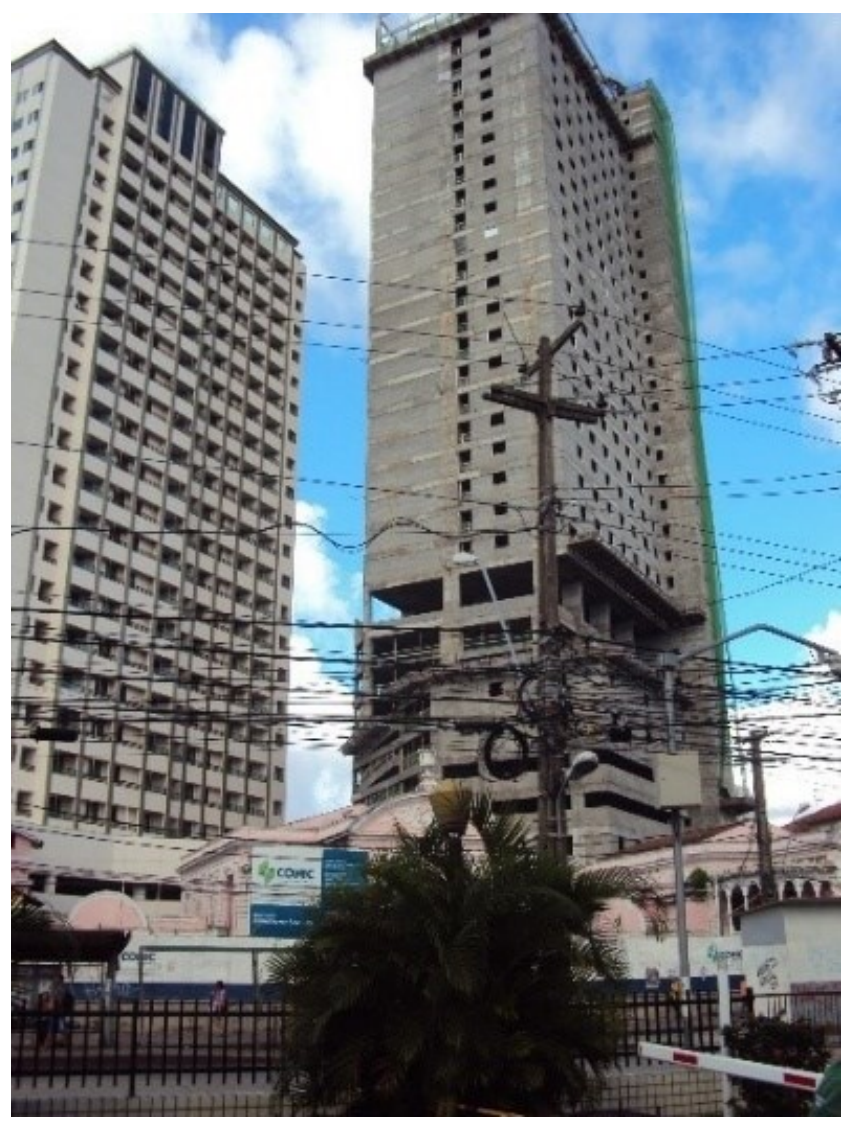

Imagem 4-Instituto de Psiquiatria Luiz Inácio, atualmente. Image 4-Institute of Psychiatry Luiz Inácio currently. Fonte: elaborada pelo autor (2016)

Pode-se notar o enorme contraste entre a edificação antiga e as novas ainda em construção, além da quebra do ritmo das aberturas. $\mathrm{Na}$ imagem 3 , visualizam-se as edificações e componentes do sanatório em seu arranjo original, com proximidade à rua, muro baixo e tipologia eclética, típica das grandes construções do final do sé- 
culo XIX e início do século XX. Com a construção das torres, a paisagem urbana ganha uma grande quantidade de informações impostas fisicamente na área. O grande número de andares transmite a noção de produtividade associada ao rápido movimento da sociedade. Isso é uma consequência direta da exaltada importância da eficácia e velocidade das ações humanas nas cidades capitalistas modernas, conduzindo o uso do espaço urbano como suficientemente capaz de imprimir o resultado das relações lucrativas de trabalho. A Paisagem urbana se faz, assim, como expressão dessa maneira de organização, onde a concepção visual se compõe pela importância do que é economicamente produtivo, fazendo do antigo sanatório algo discreto diante das torres. Por isso, quanto mais produtivo e visualmente eficiente, maior o privilégio dessas enormes construções no retrato urbano. Além dessa concepção, o lugar ocupado pelo Instituto Luiz Inácio está permeado de ativi- circulação de carros e ônibus, inserindo mais informação e agitação ao ambiente que absorve cada vez mais a estrutura.

\section{O Colégio Marista}

No terreno do Colégio Marista encontra-se uma edificação de uso comercial ativada desde 2006, o Atacado dos Presentes, à direita da antiga edificação. Além disso, o terreno possui a locação de uma outra edificação que ainda está em construção (encontra-se na fase de fundação) na parte posterior do colégio, fruto de um projeto de expansão do Atacado dos Presentes.

A edificação analisada segundo os conceitos estabelecidos por Nivaldo Andrade (2006) será a do Atacado dos Presentes, traçando um comparativo com a do antigo colégio. Em relação à outra, que anda em fase de construção, vai ser levantada uma pequena discussão sobre essas futuras instalações.

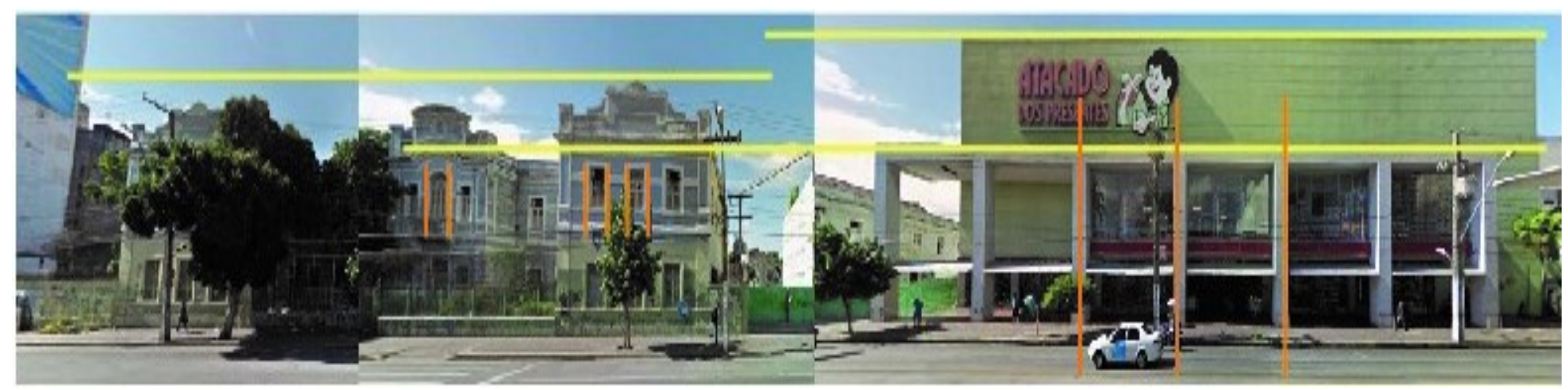

Imagem 5-Skyline mostrando a relação entre as edificações.

Image 5-Skylines showing the relationship between buildings.

Fonte: Google Maps e editado pelo autor (2016).

dades que o deixam ainda mais secundário na paisagem do Recife. Os numerosos cabos de rede elétrica presentes em boa parte da visão da antiga edificação disfarçam a configuração arquitetônica do Instituto. Assim, as pessoas que circulam na Avenida Conde da Boa Vista têm razoável dificuldade de compreender do que trata o pequeno corpo de muros em meio aos cabos e placas de trânsito. Outro fato que fortifica a timidez do sanatório na paisagem da avenida se faz pela grande
$\mathrm{Na}$ figura 5, as linhas em amarelo marcam as escalas dos edifícios. A escala da edificação nova está em consonância com a antiga, uma vez que aquela remonta à marcação do coroamento da antiga e possui quase a mesma quantidade de pavimentos, sendo pouca a diferença entre as alturas máximas. As linhas laranjas estão marcando o ritmo das edificações. A intervenção arquitetônica encontra-se em dissonância com a antiga nesse 
fator, uma vez que suas aberturas marcadas por portais não são congruentes com aquelas preexistentes do IEP.

Os materiais utilizados estão em dissonância por não se apresentarem com a mesma cor. Outra diferença marcante é que o edifício antigo não possui pastilhas de cerâmicas como a nova edificação. Em termos de densidade ou massa, a intervenção está em consonância com o IEP, já que a edificação possui característica similar à antiga, possuindo mais massa que aberturas, mais "cheios" que "vazios".

Na questão da implantação, a edificação nova está em consonância com a antiga. Isso acontece por elas estarem no mesmo parâmetro da via, como pode ser visto na imagem 6 :

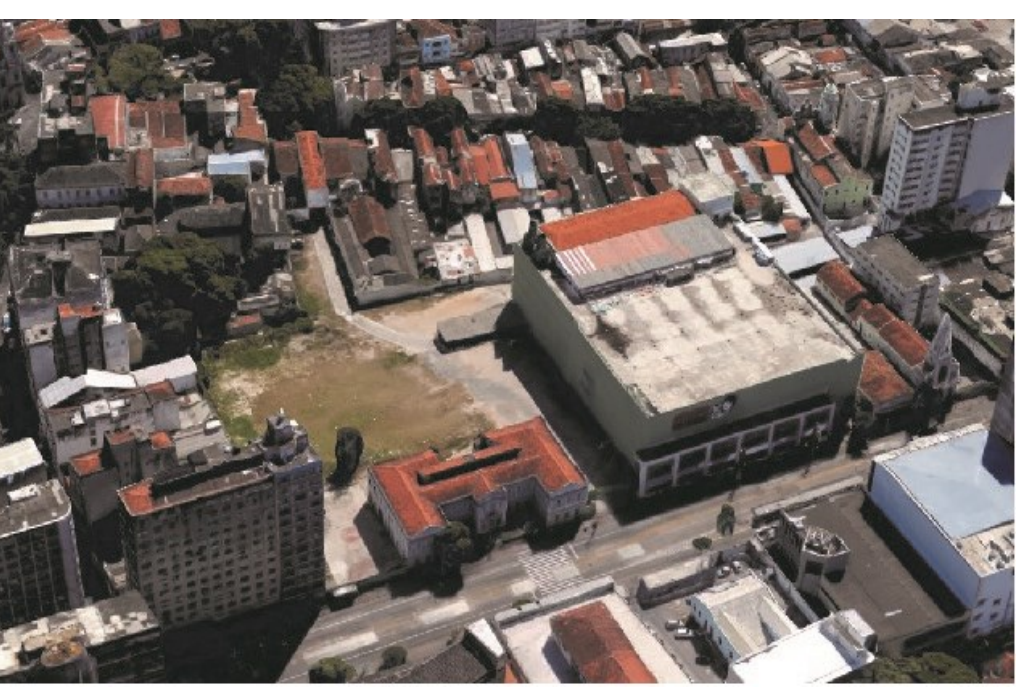

Imagem 6-Vista aérea das edificações presentes no lote 358 da Av. Conde da Boa Vista

Image 6-Aerial view of the buildings present in lot 358 of Conde da Boa Vista Avenue.

Fonte: Google Maps (2016)

Ainda na imagem 6, é possível notar a dissonância na volumetria entre a edificação recente e a antiga. $\mathrm{O}$ atacado dos Presentes possui o estilo de um edifício caixão, enquanto o Colégio Marista possui um tipo de edifício pátio.

Em relação às transformações na paisagem urbana da unidade escolar, é possível sinalizar para as relações de poder no seu entorno. A influência e poder político dos agentes proprietários dos meios de produção reflete diretamente nos sentidos que são possíveis atribuir à estrutura do colégio. O grande fluxo diário de pessoas no Atacado dos Presentes e a exposição de diversos produtos e mercadorias nas suas vitrines concedem à edificação histórica ao lado característica secundária e inferior. A sensação transmitida para a visão daqueles que circulam na Avenida Conde da Boa vista é de uma estrutura inabitada, distante das atividades corriqueiras do lugar e alheio ao avanço da vida na cidade. O distanciamento do sentido de pertença se fortalece pelas altas placas e muros que cobrem até a fachada da antiga edificação. Ironicamente, as instalações do mesmo lote recebem significados sociais e visuais completamente distintos. O claro domínio ativo do terreno por parte da empresa comercial evidencia a dinâmica das sociedades modernas voltadas à obtenção do lucro e configura o poder de determinados agentes urbanos na administração de centros de memória e história. Dessa maneira, a paisagem urbana do local é determinada pelos interesses desses agentes, imprimindo materialmente seus grandes projetos de expansão, camuflando o espaço de um passado afetivo para muitas pessoas da cidade.

\section{Futuras Instalações do Colégio Marista}

Há previsão de novas instalações no terreno do Colégio Marista, o chamado Shopping Marista, que deverá concluir suas obras em 2018. O empreendimento contará com 195 lojas, além de 520 vagas para veículos. O shopping terá três pavimentos, além de um semienterrado destinado às garagens. 
A paisagem urbana referente aos casos trabalhados receberam muitas mudanças devido às recentes instalações dos agentes sociais. Trata-se, agora, de uma percepção marcada pelos interesses desses agentes, ou seja, dos promotores imobiliários e dos grandes comerciantes. Embora permaneçam as minúsculas instalações antigas que restam (e resistem) do Colégio Marista e Instituto de Psiquiatria Luiz Inácio, a predominância desses agentes é clara. No caso do Colégio, com as futuras instalações dos grandes comerciantes, essa predominância se tornará ainda mais clara. Enfim, como identificado no conceito de paisagem, ela se faz reveladora de uma nova configuração que reflete traços da sociedade recifense. Manifestadamente, revela uma cidade que enfraquece seu prestígio significativo de paisagem formada por edificações históricas e centros de memória.

A Lei de Uso e Ocupação do Solo da Cidade do Recife (LUOS) é falha no momento em que protege apenas a edificação ou conjunto de edificações em questão (mais de uma edificação pode ser protegida por lote), e não protege de maneira adequada o seu terreno em específico. Em relação ao terreno, o máximo que a lei acerca dos Imóveis Especiais de Preservação determina é a ilegalidade do desmembramento dos terrenos com IEP's inseridos. O resultado disso é o uso do solo bastante flexível por parte dos agentes urbanos próximos a essas edificações. Os lotes e, consequentemente, seus imóveis, podem ser comprados, vendidos, remembrados e é possível a construção de novas edificações no terreno. E essas, seguindo os procedimentos da zona legislativa na qual estão inseridas (designada pela LUOS), permitem aos construtores usufruírem do uso máximo do coeficiente de construção e o mínimo das taxas de afastamento e solo natural.

A legislação dos IEP's deveria estabelecer a proibi- ção ou uma série de exigências que os projetos das novas edificações obedecessem. Como, por exemplo, seguir o gabarito máximo da edificação protegida e realizar a intervenção em sítio histórico de modo que pelo menos a fachada esteja em consonância com o IEP.

Considerando que são patrimônios históricos únicos na construção da memória da cidade, os Imóveis Especiais de Preservação precisam de um olhar mais sensível das autoridades responsáveis pela regulação das edificações e zonas do Recife. As legislações responsáveis por atuar e regular as áreas em que estão presentes, acabam não sendo eficientes no resguardo e preservação das edificações históricas e descaracterizam a própria paisagem relacionada a essas antigas construções. Como foi mostrado, existem grandes aspectos entre as novas construções que podem ser caracterizados como uma má intervenção nos terrenos das antigas edificações. Isso acarreta transformações que encaminham a cidade para uma nova personalidade, na qual a história e a memória afetiva são compreensões que se enquadram cada vez mais no âmbito do indiferente.

Esse artigo, de nenhuma maneira, esgota a discussão em torno dessas transformações que foram trabalhadas. Aqui, o foco estabeleceu-se em conhecer essas mudanças e sua influência na significação histórica das rugosidades e na paisagem urbana, a partir da criação de contraponto arquitetônico entre as antigas e novas edificações. Isso tudo embasado no atual processo legislativo referente aos IEP's e ao uso do solo na cidade do Recife. Conforme visualizado, muita coisa foi revelada, como uma certa predominância de determinados agentes no espaço urbano. Outra temática que, desde já, podese investigar, seria a perspectiva da população em relação a essas transformações nos casos do Instituto e do Colégio, visto que estes se constituem como patrimônios históricos da cidade. 


\section{Referências}

ANDRADE JÚNIOR, Nivaldo Vieira de. Metamorfose Arquitetônica. Intervenções projetuais contemporâneas sobre o patrimônio edificado. Salvador, dissertação (mestrado), Universidade Federal da Bahia, 2006.

CARLOS, Ana Fani Alessandri. A Cidade. São Paulo: Contexto, 2005.

COLÉGIO MARISTA SÃO LUIS. História. Disponível em:

$<$ https://marista.edu.br/saoluis/?page_id=1227>. Acesso em: 20 dez. 2016.

CORRÊA, Roberto Lobato. O Espaço Urbano. São Paulo: Ática, 2002.

FREITAS, Augusto. Grupo Luna, proprietário do Atacado dos Presentes, inicia obras do Shopping Marista. Diário de Pernambuco, 30 mai. 2015. Disponível em: < http://www.diariodepernambuco.com.br/app/noticia/ economia/2015/04/30/internas_economia,574279/grupo-luna-proprietario-do-atacado-dos-presentes-inicia-obrasdo-shopping-marista.shtml >. Acesso em: 15 jun. 2016.

GOMES, Edvânia Torres Aguiar. Recortes de Paisagens na Cidade do Recife: uma Abordagem Geográfica. Recife: Massangana, 2007.

LIMA, Fernanda Andrade. Saúde Mental à Luz da Psicologia Corporal. Revista Latino-Americana de Psicologia Corporal. Ano 3, No. 5, 2016, p. 08-22.

RECIFE (PE). Lei No 16. 284/97, de 22 de janeiro de 1997. Define os Imóveis Especiais de Preservação - IEP, situados no Município do Recife, estabelece as condições de preservação, assegura compensações e estímulos e dá outras providências. Disponível em: <http://www.legiscidade.recife.pe.gov.br/lei/16284/>. Acesso em: 14 jun. 2016.

RECIFE (PE). Lei N 16.176/96, de 9 de abril de 1996. Estabelece a Lei de Uso e Ocupação do Solo da Cidade do Recife. Disponível em: <http://www.legiscidade.recife.pe.gov.br/lei/16176/>. Acesso em: 14 jun. 2016.

RECIFE (PE). Lei No 17511/2008, de 29 de dezembro de 2008. Promove a revisão do Plano Diretor do Município do Recife. Disponível em:

$<$ http://www.legiscidade.recife.pe.gov.br/lei/17511/>. Acesso em: 17 de jun. 2016.

RECIFE (PE). Decreto No 26.552, de 13 de julho de 2012. Classifica os imóveis de $n^{\circ}$ s 1509, 1531 e 1533 da Av. Conde da Boa Vista, Bairro da Boa Vista, como Imóveis Especiais de Preservação. Disponível em: <http:// www.legiscidade.recife.pe.gov.br/decreto/26552/>. Acesso em: 14 jun. 2016.

RECIFE (PE). Decreto n ${ }^{\circ} 27.888$, de 09 de abril de 2014. Classifica como iep - imóvel especial de preservação o antigo colégio marista, situado na avenida conde da boa vista, $\mathrm{n}^{\circ} 358$, bairro da boa vista, neste município do recife. Disponível em:

$<$ https://leismunicipais.com.br/a/pe/r/recife/decreto/2014/2789/27888/decreto-n-27888-2014-clas

sifica-como-iep-imovel-especial-de-preservacao-o-antigo-colegio-marista-situado-na-avenida-co nde-da-boa-vista-n-358-bairro-da-boa-vista-neste-municipio-do-recife>. Acesso em: 14 jun. 2016.

SANTOS, Milton. Por uma Geografia Nova: da crítica da geografia a geografia crítica. São Paulo: Hucitec/ Edusp, 1978. tec, 1988

Metamorfoses do Espaço Habitado: fundamentos teóricos e metodológicos da geografia. São Paulo: Huci. A Natureza do Espaço: Técnica e Tempo. Razão e Emoção. São Paulo: Hucitec, 1996.

Submissão: $29 / 09 / 2017$

Aceite: $25 / 03 / 2018$ 